\title{
Health Workforce Migration in the Asia Pacific: implications for the achievement of sustainable development goals
}

\author{
SD Short, K Marcus and M Balasubramanian
}

\begin{abstract}
The maldistribution of health workers globally and within the Asia Pacific region remains problematic. While globalisation, and the increasing mobility of capital and labour, helps to reduce inequalities between countries, it increases inequality within countries. This study examines health workforce data and densities in the Asia Pacific region through a health workforce migration lens. The main implication relevant to achievement of sustainable development goals is the need for countries to work in a co-ordinated way in this region to increase substantially health financing and the recruitment, development, training and retention
\end{abstract}

of the health workforce in developing countries, especially in least developed countries and small island developing states, most notably the Maldives, TimorLeste, Kiribati, Samoa, Solomon Islands, Tuvalu and Vanuatu.

Abbreviations: OECD - Organisation of Economic Co-operation and Development; SDG - Sustainable Development Goals; SIDS - Small Island Development States.

Key words: health workforce; Migration; Asia Pacific; Sustainable Development Goals.

\section{Stephanie Short}

Deputy Director, Sydney Asia Pacific Migration Centre Faculty of Health Sciences

The University of Sydney

Sydney, New South Wales, Australia.

\section{Kanchan Marcus}

Health Systems \& Global Populations Faculty

Research Group

Faculty of Health Sciences

The University of Sydney

Sydney, New South Wales, Australia.

\section{Madhan Balasubramanian}

Australian Research Centre for Population Oral Health, School of Dentistry

Faculty of Health Sciences,

The University of Adelaide

Adelaide, South Autralia, Autralia.

Discipline of Behavioural and Social Sciences in Health,

Faculty of Health Sciences,

The University of Sydney

Sydney, New South Wales, Australia.

Correspondence:

Kanchan.marcus@sydney.edu.au
Substantially increase health financing and the recruitment, development, training and retention of the health workforce in developing countries, especially in least developed countries and small island developing states. SDG (Goal 3c)

\section{Background}

A shortage of health workers, particularly in rural areas within low and middle-income countries, constitutes a dire situation, where human resources for health are limited and large disparities in access to healthcare exist. The adaptability and resilience of global health systems was put to the test with the Ebola, MERS and Zika outbreaks. [1] Reports from the World Health Organization (WHO) estimate a global shortfall of 12.9 million healthcare workers by 2035; in 2016 the shortfall is 7.2 million. [2] The inequitable distribution of health workers within and between countries is expected to worsen in low-income countries at a time where treatable and preventable disease is of particular concern. [3] The Lancet [1] declares 'no health workforce, no global security', the health workforce is fundamental to health systems strengthening and essential in working to achieve the Sustainable Development Goals (SDGs). 
The Asia-Pacific* boasts more than half the world's population with 3.7 billion people. [4] In 2010-2011, 25 million Asian migrants shifted to Organization of Economic Cooperation and Development (OECD) countries. [5] Approximately two million highly qualified migrants moved from the Asian and Pacific countries to OECD countries, which is more than any other region in the world. [5] Global mobility of health professionals from low-to middle-to high income countries poses particular ethical challenges. Source countries face 'brain drain' issues as highly qualified health personnel migrate, impacting negatively on the developing country's education and health sector capacity to provide training, education and health services to their populations.

The United Nations has enshrined the 'right to migrate'. [6] Senior educators and health professionals have the right to migrate; yet this loss for low and middleincome countries, worsens gaps in training, and reduces health

* Our description of the Asia-Pacific includes the WHO Western Pacific and South-East Asian Regions. These regions include 38 countries. This description is due to technical reasons, based on data availability and to offer comparable estimates based on global categories put forth by the WHO. care access for communities. Migration movements also show no sign of abatement as bilateral and multilateral agreements ease the flow of cross-border mobility. [7] Health workers also move within their own countries from rural to urban areas, thereby diminishing healthcare access for regional and remote communities. An ageing population, particularly evident in many high-income countries, further leads to complex health presentations and a greater need for skilled health personnel.

Health personnel (especially doctors, nurses and dentists) are fundamental to strengthening a country's health system, $[1,8]$ as they deliver primary care services on the ground for prevention, diagnosis and treatment. This is essential in reducing the spread of infectious diseases such as the Zika virus, which has been reported in the Asia Pacific region, and in reducing the global burden of non-communicable diseases. Health workforce remains a key SDG (Goal 3c);

Substantially increase health financing and the recruitment, development, training and retention of the health workforce in developing countries, especially in least developed countries and small island developing states.

Figure 1: Median density of health workforce per 10,000 population by WHO Regions, 2000-2013

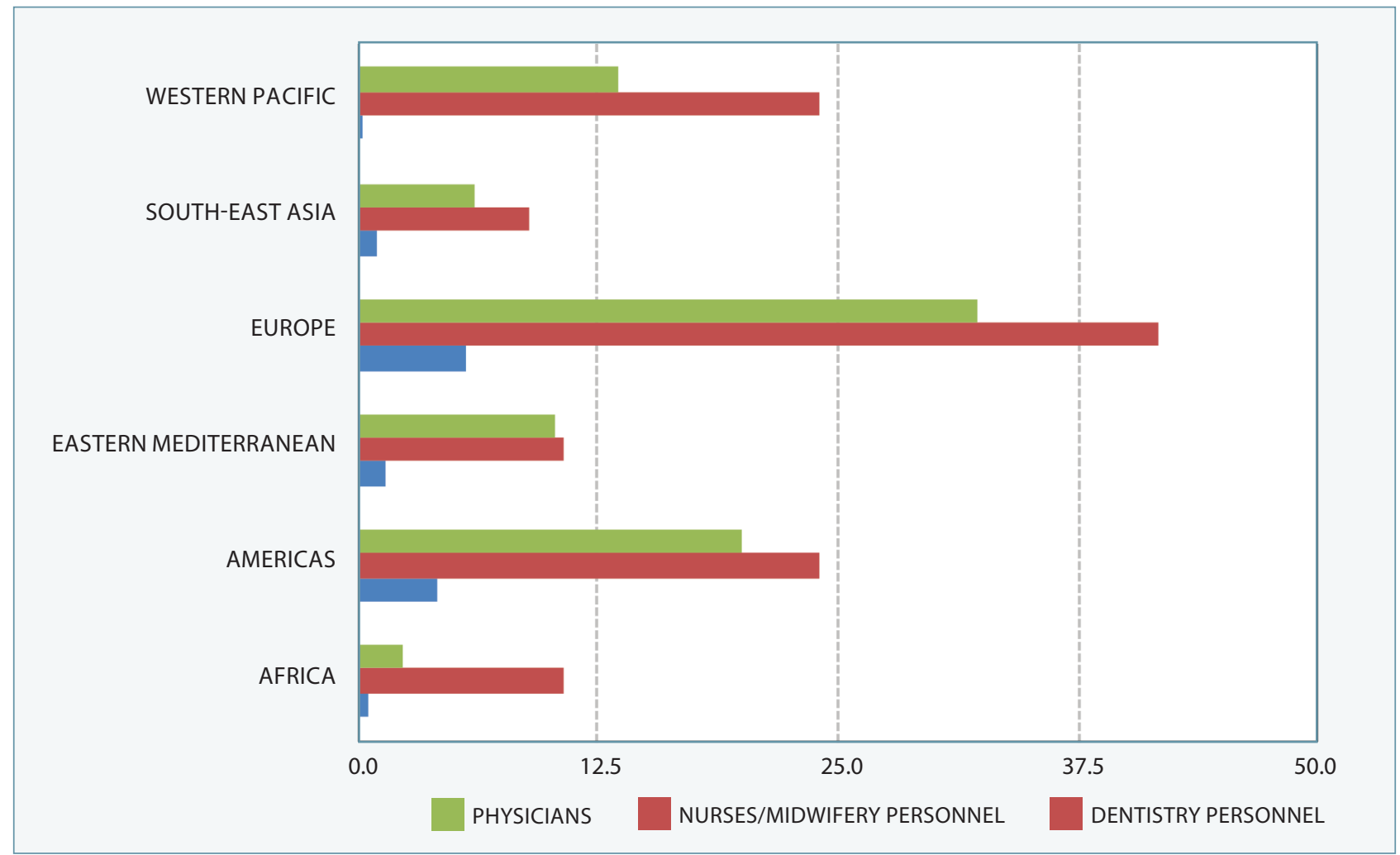

Source: Adapted from the World Health Organization. World Health Statistics 2016: Monitoring for the SDGs. Report

Notes: (a) Data points were not uniform for all countries, and ranged from 2000 to 2013. (b) In many countries the distinction between nursing and midwifery personnel was difficult to distinguish based on how the data was collected (b) Dentistry personnel includes both dentists and allied oral health workforce. 
This paper provides a critical analysis of the maldistribution of health professionals in the Asia Pacific region within the context of SDGs through a health workforce migration lens. We focus in this paper on doctors, nurses and dentists, three highly mobile health care professions.

\section{Health workforce challenges in the Asia Pacific Region}

Globally it is estimated that there are about 43 million health workers, including 9.8 million physicians, 20.7 million nurses/midwifes and 13 million other health workers. [9] Figure 1 illustrates the median density of health workforce (physicians, nurses/midwifes and dentistry) personnel for the six WHO Regions. While the European and American Region reported some of the highest densities in all three professional groups, the South East Asian and African Regions reported the lowest. There were 24.1 nurses per 10,000 population in the Western Pacific Region (above the global average of 17.6); however, the Western Pacific Region reported the lowest density of dentistry personnel $(0.2$ dentistry personnel per 10,000 population). The SouthEast Asian Region reported the lowest nursing/midwifery personnel density (9.0 per 10,000 population), when compared to all other regions. Furthermore, physicians in the South East Asian Region were only 6.1 per 10,000 population while the global average was 12.3 physicians per 10,000 population.

In order to better understand the health workforce situation in the Asia Pacific Region, we examine the health worker density for all the 38 countries in the WHO Western Pacific and South-East Asian Region (see Table 1). Fourteen countries in the Region have less than five physicians per 10,000 population; twelve countries have a density of less than one dentist per 10,000 population. While Australia, New Zealand and Japan reported the highest nursing/ midwifery personnel density, the densities were lowest in the Pacific Islands, the Indian subcontinent and the East Asian region. Figure 1 suggests South East Asia faces a more substantial health workforce challenge than the Western Pacific region. However, when we examine the data for each country within these two regions, we see a different story (Table 1). We see greater diversity within the Western Pacific, and in particular serious challenges with maldistribution in the following Pacific Islands: Fiji; the Marshall Islands; Niue; Papua New Guinea; Solomon Islands; and Vanuatu.

Within the Asia Pacific Region workforce shortages and maldistribution are most acute in Papua New Guinea, TimorLeste and Myanmar. [10] Life expectancy statistics reveal a 20- year difference between high-income countries (80 years) and low-middle income countries (60 years). [10]

The International Organization for Migration Regional Strategy Report for Asia and the Pacific 2012-2015, [4] confirms that the Philippines remains the leading labour sending country in the Asia Pacific region; even though the report anticipates South Asia to have the largest workforce in the world by 2050. It is widely recognised that the Philippines purposely overproduces nurses $[11,12]$ as a

Table 1: Health workforce density per 10,000 population in the Asia Pacific Region

\begin{tabular}{|lcccc|}
\hline WHO REGION/COUNTRY & YEAR & $\begin{array}{c}\text { PHYSICIANS } \\
\text { PERSONNEL }\end{array}$ & $\begin{array}{c}\text { NURSES/MIDWIFERY } \\
\text { PERSONNEL }\end{array}$ & DENTISTRY \\
\hline South-East Asian Region & & & & 0.3 \\
Bangladesh (LDC) & 2011 & 3.6 & 2.2 & 0.3 \\
Bhutan (LDC) & 2007 & 0.6 & 2.4 & 3.7 \\
DPR Korea & 2003 & 32.9 & 4.2 & 1.0 \\
India & 2011 & 7.4 & 17.1 & 1.0 \\
Indonesia & 2012 & 2.0 & 13.8 & 0.9 \\
Maldives (SIDS) (LDC) & 2010 & 14.2 & 50.4 & 0.7 \\
Myanmar (LDC) & 2012 & 6.1 & 10.0 & 0.1 \\
Nepal (LDC) & 2004 & 2.1 & 4.6 & 0.5 \\
Sri Lanka & 2010 & 6.8 & 16.4 & 2.6 \\
Thailand & 2010 & 3.9 & 20.8 & 0.4 \\
Timor-Leste (SIDS) (LDC) & 2011 & 0.7 & 11.1 & 0.5 \\
\hline
\end{tabular}


Table 1: Health workforce density per 10,000 population in the Asia Pacific Region continued

\begin{tabular}{|c|c|c|c|c|}
\hline WHO REGION/COUNTRY & YEAR & $\begin{array}{l}\text { PHYSICIANS } \\
\text { PERSONNEL }\end{array}$ & $\begin{array}{l}\text { NURSES/MIDWIFERY } \\
\text { PERSONNEL }\end{array}$ & DENTISTRY \\
\hline \multicolumn{5}{|l|}{ Western Pacific Region } \\
\hline Australia & 2011 & 32.7 & 106.5 & 5.4 \\
\hline Brunei Darussalam & 2012 & 14.4 & 80.5 & 4.2 \\
\hline Cambodia (LDC) & 2012 & 1.7 & 7.9 & 0.2 \\
\hline China & 2001 & 10.6 & 10.8 & 1.1 \\
\hline Cook Islands (SIDS) & 2009 & 13.3 & 64.4 & 10.6 \\
\hline Fiji (SIDS) & 2009 & 4.3 & 22.4 & 2.0 \\
\hline Japan & 2010 & 23.0 & 108.6 & 7.9 \\
\hline Kiribati (SIDS) (LDC) & 2008 & 2.4 & 34.4 & 1.7 \\
\hline Lao PDR (LDC) & 2012 & 1.8 & 8.8 & 0.4 \\
\hline Malaysia & 2010 & 12.0 & 32.8 & 3.6 \\
\hline Marshall Islands (SIDS) & 2008 & 4.6 & 26.0 & 1.6 \\
\hline Micronesia (Fed. States of) (SIDS) & 2008 & 5.7 & 24.8 & 3.5 \\
\hline Mongolia & 2011 & 28.4 & 36.2 & 2.3 \\
\hline Nauru (SIDS) & 2008 & 7.1 & 49.3 & 0.7 \\
\hline New Zealand & 2007 & 23.8 & 108.7 & 4.6 \\
\hline Palau (SIDS) & 1998 & 14.4 & 62.8 & 13.3 \\
\hline Papua New Guinea (SIDS) & 2008 & 0.5 & 4.6 & 0.1 \\
\hline Philippines & 2004 & 11.5 & 60.0 & 5.6 \\
\hline Republic of Korea & 2012 & 21.4 & 50.1 & 4.5 \\
\hline Samoa (SIDS) (LDC) & 2008 & 4.5 & 18.5 & 3.4 \\
\hline Singapore (SIDS) & 2013 & 19.5 & 57.6 & 4.1 \\
\hline Solomon Islands (SIDS) (LDC) & 2005 & 1.9 & 14.5 & 1.1 \\
\hline Tonga (SIDS) & 2009 & 6.0 & 36.7 & 3.6 \\
\hline Tuvalu (SIDS) (LDC) & 2008 & 9.1 & 58.2 & 3.6 \\
\hline Vanuatu (SIDS) (LDC) & 2008 & .2 & 17.0 & 0.1 \\
\hline Vietnam & 2013 & 11.9 & 12.4 & NA \\
\hline
\end{tabular}

Source: The 2014 update, Global Health Workforce Statistics, World Health Organization, Geneva

Notes: (a) The Asia-Pacific Region includes the World Health Organization's South-East Asian and Western Pacific Regions. (b) Data points were not uniform for all countries, and ranged from 1998 to 2013. We have selected the latest available data point, where densities for all three professions were available. (c) In many countries the distinction between nursing and midwifery personnel was difficult to distinguish based on how the data was collected (d) Dentistry personnel includes both dentists and allied oral health workforce. (e) Niue (SIDS) has been removed from the table, as the population was too small to make the workforce density estimates meaningful. (f) LDC = least developed countries; SIDS = small island developing states. 
matter of foreign policy in order to attract remittances from overseas nurses. These nurses emigrate in order to respond to nursing shortages in the Middle East, Britain, Canada and Australia. India and Indonesia also supply health workers to neighbouring countries, as well as urban cities within the region and/or other developed countries. This global chain of care links Asia to neighbouring countries; Fijians migrate to Palau, Indian nurses migrate to the Gulf, Indonesians migrate to Japan and so forth. [10]

Asian countries also serve as destination countries as migrant health workers move to Singapore, Thailand and Malaysia [7] while agreements such as the Association of Southeast Asian Nations encourage mobility within the region. [13] Health worker mobility is becoming increasingly circular and complex [14] as health migrants passage between several transit countries, possibly return home for a short period before migrating to other transit or destination countries. This may provide benefits of return migration where skills and expertise can be shared in the region, however the benefit is likely to be short lived, as most health workers reapply for work in other countries.

The influential WHO 2006 World Health Report, [8] 'Working together for health' emphasised the significance of the link between health worker density and primary healthcare access - in other words, a greater number of health workers, results in better public health access and health outcomes for a county.

The reasons underpinning health worker migration are well documented [11,10,12,15-17] financial, lifestyle, security, better work conditions, training opportunities and so forth. Unfortunately, underinvestment in health by governments, and political unrest, may further contribute to the migration of health workers out of developing countries in the region. This was evident following the 1987 Asian financial crisis and the 2000 coup in Fiji, which saw health workers leave the country. [18] This uneven distribution of workers creates greater levels of disparity and inequalities, particularly for low-income countries in the region. Further skills recognition for Asia Pacific nurses, doctors and dentists could present deskilling problems, as Australia, United Kingdom, Canada and many developed countries require bridging or skills assessment, prior to gaining work in the transit or destination country. [19]

\section{The Philippines}

The Philippines is the key contributor in supplying nurses and midwives worldwide. Between 1993-2010, 29\% of the total number of health professionals who worked overseas were nurses. [20] During the 1990s and early 2000s, the Philippines Government policy to export nurses in exchange for remittances, boosted the economic situation of the country. This led to an increased demand among nursing students and then an oversupply of nursing schools, which reduced the quality of nursing graduates. However, the final nursing license examination and action by governing bodies eventually closed poor performing nursing schools. Surprisingly, the country saw a reduction in medical school students, as doctors retrained as nurses in order to gain greater migration opportunities. Since most senior nurses migrate due to inevitable push factors, too often junior trainee nurses are left unsupervised, placing patients at risk. [12]

The Middle East remains a popular transit region for Filipino nurses. An estimated 90,382 Filipino nurses were employed in Saudi Arabia between 1993-2010. Permanent residency is not permissible in Middle East countries and nursing contracts are generally two-years in duration. Contracts are either renewed or otherwise the nurse returns to the Philippines - where they apply for work in another country. A substantial drop in United States migration occurred following 9/11 due to tightened security in the United States, while a drop in Filipino migration to the United Kingdom has resulted in neighbouring countries like Spain and Portugal seeing their nurses migrate to the United Kingdom. [21]

\section{The Pacific Islands}

Fiji has one of the largest healthcare systems in the Western Pacific region and has been most affected by emigration of health professionals. Fiji reported the loss of 160 qualified doctors between 2003-2007 and 40 doctors in 2004 alone. [23] Fiji also ranked worse on the human development index, a clear indication that a loss of health workers impacts negatively on the health and welfare of the country's citizens. [9] A number of small island developing states in the Pacific, failed to reach Millennium Development Goals due to small island developing states' unique vulnerabilities in size, economic standing and maldistribution of the workforce (see Table 1).

\section{Skilled health workforce migration into Australia}

Migrant health workers occupy a significant proportion of the Australian health workforce. According to a study by the Organization for Economic Cooperation and Development (OECD), Australia reports some of the highest percentages of foreign-born doctors, nurses and dentists. [22,24] Immigration policies are highly selective in choosing highly-skilled and well-educated health workers from other 
countries. In the last decade, Australia's skilled migration policy has transformed health workforce planning whereby the temporary 457 visa has dramatically expanded and employers continue to recruit migrant workers without any cap. Permanent skilled migration no longer dominates but the study-migration pathway has rapidly strengthened. [19] A goal for domestic self-sufficiency by 2025 was set by Australian Health Ministers, yet a significant workforce gap of 85,000 nurses and 2,500 doctors is predicted by 2025 . $[25,26]$ By 2030 , it is estimated that this shortfall will increase to 123,00 nurses and 5,000 doctors. $[25,26]$

In Australia the maldistribution of the health workforce is most pronounced in rural and remote areas, as few local graduates choose rural work or commit to less attractive areas of specialisation such as aged care. Excluding the medical sector, limited rural incentive programs exist in other health professions and thus migrant health workers can be recruited to these areas of shortage. According to Rural Health Workforce Australia, international migrant health professionals are central in redressing Australia's rural health inequality as they fundamentally contribute to achieving universal health coverage in Australian remote communities that would otherwise lack access to health resources or services. Despite an increase in domestic training of health graduates, according to the ABS (2014), 47\% of Australians with medical degrees, $59 \%$ of dentists, and $29 \%$ of nurses were overseas born. Asian developing countries; India, the Philippines and China remain the dominant source countries for migrant health workers in Australia.

\section{Sustainable Development Goals (SDGs) and Universal Health Coverage}

The Sustainable Development Goals place particular focus on universal health coverage, in order to achieve equitable access to healthcare globally. In 2015, the United Nations established a Task Team who set a framework, which includes economic, social, health, environmental, and sustainability dimensions for the next 15 years. Seventeen SDGs were devised which address ongoing MDGs, including redressing equity and inequality within and among countries. Human resources for health is recognised as a key SDG to achieve universal health coverage, as all should be able to access healthcare without suffering financial hardship when paying for them. [27] Universal health coverage includes health promotion, prevention and treatment, rehabilitation and palliative care. [9]
Attention to monitoring performance and the ongoing maintenance of professional standards is required by all countries in the Region. The health workforce needs to be adequately supported, equitably distributed, highly trained, available in areas of need and empowered to deliver quality health services for SDGs to translate to practice. This requires health governance strategies relevant to health workforce planning, retention, distribution and sustainability at national, regional and global levels.

The WHO 69th World Health Assembly endorsed the Global Strategy on Human Resources for Health: Workforce 2030. [27] The purpose of the strategy is to improve population health outcomes, through socio-economic developments relating to the SDGs. Objective two encourages countries to invest in human resources and improve the distribution of health workers by reducing dependency on foreign trained health workers by 2030 .

The SDGs provide a framework for countries to achieve population health outcomes, emphasising a focus on the world's poorest and marginalised countries (least developed countries), and small island developing states (SIDS) (see Table 1). Health professional migration within South East Asia and the Western Pacific region has become more circular and complex as traditional migration patterns have changed. Health inequity and access highlight the need for country's to reinvest in health workers in order to achieve the'right' balance of skilled health workers, especially in rural areas. The Asia-Pacific region experiences vast differences in economic, social and financial standing, this paper contends that the sustainable development goals (SDGs) provide guidance for strengthening the health workforce, so that all countries, within the context of increasing interdependence in a globalising world, particularly least developed countries and small island states, can work towards achieving universal health coverage by 2030 .

\section{References}

1. Heymann D. No health workforce, no global health security. Lancet [Internet]. 2016;387(10033):2063. Available from: http:// dx.doi.org/10.1016/S0140-6736(16)30598-0

2. Campbell J, Dussault G, Buchan J, Pozo-Martin F, Guerra Arias M, Leone $C$, et al. A universal truth: no health without a workforce. 2013;104.

3. Perry $\mathrm{H}$, Zullinger R, Rogers $\mathrm{M}$. Community health workers in LowMiddle- and High-income countries: an overview of their history, recent evolution and current effectiveness. Annu Rev Public Health. 2014;35:339-421.

4. International Organisation for Migration. Regional Strategy for Asia and the Pacific 2012-2015 [Internet]. 2015. Available from: https://www.iom.int/sites/default/files/country/docs/AUP00548RO-Bangkok-Regional-Strategy.pdf 
5. Asia-Pacific Thematic Working Group (APTWG) on International Migration. Asia-Pacific Migration Report 2015: Migrants' contributions to development [Internet]. 2015. Available from: http://www.unescap.org/sites/default/files/SDD AP Migration Report report v6-1-E.pdf

6. United Nations General Assembly. Universal declaration of human rights. UN Gen Assem Resolut 217 A 10 December 1948 [Internet] 1948; Available from: http://www.refworld.org/docid/3ae6b3712c html

7. Hugo G. International labour migration and migration policies in Southeast Asia. Asian J Soc Sci. 2012;40(4):392-418.

8. World Health Organization. Working Together for Health: The World Health Report. World Health Report. Geneva; 2006.

9. World Health Organisation. World Health Statistics 2016: Monitoring for the SDGs. 2016;1-79. Available from: http://www. who.int/gho/publications/world_health_statistics/EN_WHSO8_ Full.pdf

10. Connell J. Migration of health workers in the Asia-Pacific Region [Internet]. Sydney; 2010. Available from: https://sphcm.med.unsw. edu.au/sites/default/files/sphcm/Centres_and_Units/HWM_ AsiaPacific_Report.pdf

11. International Labour Office. Migration of health workers: country case study Philippines. Geneva; 2006. Report No: Working Paper (WP.236).

12. Marcus K, Short S, Nardi B. 'Hardworkers': Filipino Nurses' professional practice in Queensland. Asia Pacific J Heal Manag. 2014;9(1):28-34

13. Association of South East Asian Nations. ASEAN Economic Community [Internet]. 2015 [cited 2015 Jan 15]. Available from: http://www.asean.org/communities/aseaneconomic-community

14. Hawthorne L. Circular migration of health professionals: Policy Brief 1.2014.

15. Bourgeault IL, Labonté R, Packer C, Runnels V, Tomblin Murphy G. Knowledge and potential impact of the WHO Global code of practice on the international recruitment of health personnel: Does it matter for source and destination country stakeholders? Hum Resour Health [Internet]. 2016;14(S1):25. Available from: http://humanresources-health.biomedcentral.com/articles/ 10.1186/s12960-016-0128-5

16. Marcus K, Quimson G, Short SD. Source country perceptions, experiences, and recommendations regarding health workforce migration: a case study from the Philippines. Hum Resour Health [Internet]. 2014 Dec 31;12(1):62. Available from:http://humanresources-health.biomedcentral.com/articles/10.1186/ 1478-4491-12-62

17. Balasubramanian M, Brennan DS, Spencer AJ, Short SD. The 'global interconnectedness' of dentist migration: a qualitative study of the life-stories of international dental graduates in Australia. Health Policy Plan [Internet]. 2015;30(4):432-41. Available from: http:// heapol.oxfordjournals.org/content/early/2014/05/10/heapol. czu032.full

18. Oman K, Mounds R, Usher K. Specialist training in Fiji: Why do graduates migrate, and why do they remain? A qualitative study. Hum Resour Health. 2009;7(9).

19. Hawthorne L. WHO four-country study: Health workforce migration in Australia. In: Siyam A, Roberto Dal Poz M, editors. Migration of Health Workers: WHO Code of Practice and the Global Economic Crisis. 2014. p. 109-32.

20. Li X, Zhu K, Liu F, Li H. Assessment of quality of life in giant ameloblastoma adolescent patients who have had mandible defects reconstructed with a free fibula flap. World J Surg Oncol. 2014/07/10. 2014;12:201.
21. OECD. Workforce Policies in OECD Countries: Right jobs, right skills, right places. Paris: OECD Publishing Paris; 2016.

22. Balasubramanian M, Brennan DS, Spencer AJ, Short S. The international migration of dentists: directions for research and policy. Community Dent Oral Epidemiol [Internet]. 2016;44(4): 301-12. Available from: http://onlinelibrary.wiley.com/doi/ 10.1111/cdoe.12223/full

23. Fiji Sun. Migration sapa Fiji doctor numbers. Newspaper in BBC Monitoring Asia Pacific. 2008;

24. OECD. Immigrant Health Workers in OECD Countries in the Broader Context of Highly Skilled Migration *. Dumont J-C, Zurn P, editors. 2007.

25. Health Workforce Australia. Australia's future health workforce Nurses overview report. 2014.

26. Health Workforce Australia. Australia's Future Health Workforce Doctors Report. 2014.

27. World Health Organization. Global Strategy on Human Resources for Health [Internet]. 2015. Available from: http://www.who.int/ workforcealliance/media/news/2014/consultation_globstrat_hrh/en/ 